60

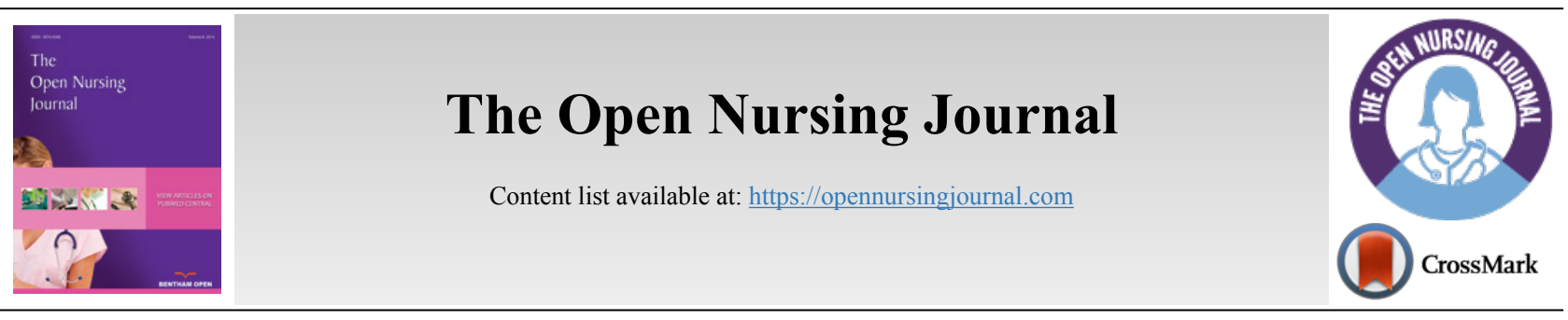

RESEARCH ARTICLE

\title{
Barriers of Nurse Collaboration for the Care of Acute Coronary Syndrome Patients in Emergency Departments: A Pilot Study
}

Titin Andri Wihastuti ${ }^{1}$, Ida Rahmawati ${ }^{1}$, Septi Dewi Rachmawati ${ }^{1}$, Yulia Candra Lestari ${ }^{2}$ and Kumboyono Kumboyono ${ }^{1, *}$

${ }^{1}$ School of Nursing, Medical Faculty, Brawijaya University; Malang, East Java, Indonesia

${ }^{2}$ School of Nursing, Kendedes Institute of Health Sciences; Malang, East Java, Indonesia

\begin{abstract}
:
Introduction:

Acute Coronary Syndrome (ACS) is a cardiovascular disease that is one of the main causes of death worldwide. Nurse collaboration in Indonesia is still very complex and inadequate. Positive collaboration in providing care for patients with ACS is essential in the practice of nursing services.

Objective:

This study aims to explore the barriers in the implementation of nurses-physicians collaboration for the care of patient with ACS in Emergency Departments (EDs)

Method:

This research is a qualitative survey using purposive sampling. It was conducted on 16 nurses who worked in emergency departments from four general hospitals in East Java, Indonesia. Research data were collected using open-ended questions in semi-structured interviews.

Results:

There were three themes obtained from the data analysis, which include the difference of confidence between senior and junior nurses in ACS actions, limitations in performing professional nursing, and unclear job responsibilities.

\section{Conclusions:}

Collaboration of nurses and physicians in emergency departments still faces many problems. It is important to carry out interprofessional education initiations for nursing and medical students, apply peer-mentoring to increase the self-confidence of junior nurse, develop and train the clinical pathway of collaboration between physicians and nurses for the care of ACS patients in EDs.
\end{abstract}

Keywords: Acute coronary syndrome, Collaboration, Emergency nursing, Interprofessional, Physician, Barriers.

\begin{tabular}{l|l|l|l}
\hline Article History & Received: September 11,2018 & Revised: November 22, 2018 & Accepted: December 10, 2018
\end{tabular}

\section{INTRODUCTION}

Collaboration among nurses, as well as between nurses and physicians is an important element of health care [1]. It is an essential method for improving the quality of health, safety, patient satisfaction and employment. Acute Coronary Syndrome (ACS) is a part of CHD (Chronic Heart Disease) which causes an increase of around $1.6 \%$ in morbidity and mortality [2]. Appropriate management based on guidelines is

Address correspondence to this author at the School of Nursing, Medical Faculty, Universitas Brawijaya, Indonesia; Tel: +6281805004106; Fax: +62 0341 564755; E-mails: abu hilmi.fk@ub.ac.id, publikasikoe@gmail.com able to reduce death and morbidity related to ACS [3]. ACS patients need quick and proper help when reaching to the Emergency Departments (EDs) due to the limitation of patients' golden period. Treatment of ACS patients in EDs should be based on collaboration because this is a complex case.

The nurse-physician collaboration system in Indonesian emergency room is very complicated. The system of collaboration consists of structure, process and results [4]. Structurally, nurses and doctors have agreed on the importance of collaborating in caring for ACS patients in EDs [5, 6]. However, there are difficulties in carrying out the collaboration 
process. The collaboration process could be recognized by aspects of assertiveness, autonomy and cooperation [7, 8]. Indonesian nurses are only able to identify the signs and symptoms as well as the proper management of ACS. However, the nurses felt that autonomy was limited. A study conducted by Moore Weaver revealed that many nurses resigned because of the bad cooperation between nurses in the room as well as bad interpersonal relationships with medical teams $[9,10]$. This is in line with a literature review by Milton, which showed that the patterns of relationship and communication between nurses in the room are still lacking $[11,12]$.

Collaboration between nurses and physicians has also attracted attention because physicians and nurses are essential in providing good quality health care. If there are problems related to the collaboration, they will affect the service performed [13, 14]. Therefore, an evaluation of nursing management is needed in order to create a positive atmosphere. The purpose of this study is to explore the process barriers of nurses-physicians collaboration for the care of ACS patients in EDs. The novelty of the results of this study is expected to be able to answer the research question: "What are the obstacles to assertiveness, autonomy, and cooperation in the process of collaborating nurses-physicians for the care of ACS patients in EDs?

\section{MATERIAL AND METHODS}

This research used a qualitative survey. The design is used to establish the meaningful diversity of some topic of interest within a population [15]. In the context of this study, the topic of interest was exploring the barriers in the implementation of nurses-physicians collaboration for the care of the patients with ACS in Emergency Departments (EDs). The inductive analysis approach is applied to identify keywords, sub-themes and themes from the results of interviews with the participants. The research was conducted from September to December 2017 in emergency departments at four general hospitals, East Java, Indonesia. Sixteen nurse participants were recruited using purposive sampling. Purposive sampling is a selection participant technique based on predetermined criteria [16]. The recruited nurses as participants were those still actively providing services for ACS patients, having work experience in EDs for the last year, and having Basic Trauma and Cardiac Life Support (BTCLS) certificate. Participants who meet these criteria are selected until data saturation is reached.

\subsection{Data Collection and, nstrument}

For collecting research data, the researcher used semistructured interviews (Table 1). All interviews were audiorecorded using a smartphone. The researcher did not know the participants before. The selection of the participants was assisted by one of the nurses in the EDs. The interviews were conducted in the EDs based on the mutual agreement; the interview time was between 30 and 60 minutes. The ethical principle was applied in this study by ensuring confidentiality and providing equal opportunity as the study progresses.

\subsection{Data Analysis}

The researcher analyzed the data using the Van Kaam method to illustrate and interpret the meaning of process barriers experienced by nurses in collaborating with physicians for the care of ACS patients in EDs. The steps of Van Kaam data analysis are as follows: (a) create a list of participants' expressions or answers, (b) perform reduction and elimination of answers, (c) categorize and create sub-themes based on categories, (d) create validation and re-identifying sub-themes that have been determined, and ending with theme determination, (e) describe the text, which is the statement of each participant showing a phenomenon, (f) give a description of the structural meaning of how the phenomenon occurs, and (g) provide a narrative explanation of the essence of a phenomenon under study and gaining meanings of the participants' experience through the phenomenon. The results of the data analysis are presented in the form of charts and narratives $[17,18]$. Keywords, sub-themes and themes of the meaning of participants' experience through the phenomenon are presented in tables and narratives to make them easier to understand.

\section{RESULTS}

The results of this study are answers to the research questions which are tied to the demographic characteristics of nurses as participants of the study. The characteristics of the participants who took part in this study were observed nurses who were aged from 25 years to 58 years; eight males and eight females; bachelor of science in nursing was five participants, and eleven participants had associate degree in nursing; five participants had worked in ED for less than or equal to ten years; eleven participants had worked greater than ten years, and all participants have a BTCLS certificate.

There are three themes in this research, which are (a) difference of confidence between senior and junior nurses in caring for ACS patients, (b) limitation for performing professional nursing practice, and (c) unclear nursing job description (Tables 2 to 4). The abbreviations (P1), (P2), (P3) in the text, represent Participant-1, 2, 3, etc.

\subsection{Difference Of Confidence Between Senior And Junior Nurses In Caring For Acs Patients}

The participants' answers to the following questions demonstrated nurses' assertiveness in their ability to care for ACS patients in EDs.

The question was, "What did you feel when handling ACS patients in EDs?"

The theme revealed the difference in readiness of the two groups namely senior and junior nurses in collaborating with physicians for the treatment of ACS patients in EDs. The results of interviews showed that Participant- 4 and Participant- 8 as senior nurses were assumed to make minimal mistakes in caring for ACS patients. The statements of Participant-4, Participant-9, Participant-11, and Participant-15 indicated that junior nurses were less confident and more confused when handling ACS patients (Table 2). 


\subsection{Limitation For Performing Professional Nursing Practice}

Limitation for performing professional nursing practice illustrated the barriers innurse autonomy in collaboration with physicians for the care of ACS patients in EDs.

The question was, "What were the limitations of the authority that you experience in collaborating with physicians to treat with ACS patients in EDs?"

There were two subthemes of obstacles in the implementation of autonomy experienced by nurses for the care of ACS patients in EDs. First, the limited authority to address triage decision making was revealed by comment Participant-2 and Participant-7. Second, the limited chance of nursing documentation was shown by statement Participant-12 and Participant-15 (Table 3).

Table 1. Themes, sub-themes, and participants' statements.

\subsection{Unclear Nursing Job Description}

The theme demonstrated the nurses' perceptions of the duty, which were formed after cooperating with health professionals in treating patients with ACS.

The question was, "How is the implementation of cooperation between health professionals for the care of ACS patients in EDs?"

The participant's response to the question informed that nurses haven't been able to cooperate with health professionals because of the obscurity of nurses' job descriptions. The job duties among health workers remained overlapping and were stated by Participant-5, Participant-9, and Participant-11. The comments of Participant-4 and Participant-12 indicated that male nurses do more services than female nurses (Table 4).

\begin{tabular}{|c|c|c|}
\hline Theme & Sub-theme & Participant' statement/keyword \\
\hline \multirow[t]{2}{*}{$\begin{array}{l}\text { 1. Difference of } \\
\text { confidence between } \\
\text { senior and junior } \\
\text { nurses in caring for } \\
\text { ACS patients }\end{array}$} & $\begin{array}{l}\text { Senior nurses note that the } \\
\text { mistakes made were } \\
\text { minimal }\end{array}$ & $\begin{array}{l}\text { "If there is a case of ACS, as far as I know, it is handled by senior nurses. Based on our } \\
\text { experience, the senior has only a minimal error rate once... (P4) } \\
\text { "Expertise maybe depends on the experience of handling ACS. Our nurses, ventilator and } \\
\text { defibrillators are already here in } 24 \text { hours. It is important, we must know where we work. We } \\
\text { learn to understand what is happening and must know the procedure to avoid mistakes." (P8) }\end{array}$ \\
\hline & $\begin{array}{l}\text { Junior nurses are less } \\
\text { confident and more confused }\end{array}$ & $\begin{array}{l}\text { Generally, the juniors activities include administering an intravenous infusion, providing } \\
\text { something, just like that. Here, we need a fast response, } 4 \text { minutes or } 5 \text { minutes, junior nurses } \\
\text { often get doubt and face obstacles to follow the speed." (P4) } \\
\text { "I am still afraid and confused to do collaboration, because I just joined the ED." (P9) } \\
\text { "If there are too many patients, usually for treating ACS patients, I consult with a more senior } \\
\text { nurse. } \\
\text { I help the patient as much as I can do such as apply an infusion therapy or ECG. Sometime I got } \\
\text { less confident because I have little experience about the ECG procedure." (PII) "Even junior } \\
\text { nurses held bachelor degree, they cannot be guaranteed in understanding ACS, this may } \\
\text { happened because they were newbies as emergency nurses, so we as senior nurses should hold } \\
\text { more roles and guide them." (P15) }\end{array}$ \\
\hline \multirow[t]{2}{*}{$\begin{array}{l}\text { 2. Limitation for } \\
\text { performing } \\
\text { professional nursing } \\
\text { practice }\end{array}$} & $\begin{array}{l}\text { Limited authority to address } \\
\text { triage decision making }\end{array}$ & $\begin{array}{l}\text { "There is an emergency physician. So sorry, it seems that our presence are ignored. We have to } \\
\text { waiting for the physician order..." (P2) } \\
\text { "So, who is the responsible person for determining ACS patients in the first priority, or the } \\
\text { second priority? It is a right of the physician, nurses have limited authority. If the doctor is } \\
\text { wrong, however, the nurse has to straighten it up." (P7) }\end{array}$ \\
\hline & $\begin{array}{l}\text { Limited chance of nursing } \\
\text { documentation }\end{array}$ & $\begin{array}{l}\text { "The medical record will be carried by the cardiologist lead to difficulties to completed the } \\
\text { nursing documentation as the forms have to filled are incorporated in the medical record." } \\
\text { (P12) } \\
\text { "Then another constraint is the patient' medical record is often be carried by the physician ." } \\
(P 15)\end{array}$ \\
\hline \multirow[t]{2}{*}{$\begin{array}{l}\text { 3. Unclear nursing } \\
\text { job description }\end{array}$} & The job duties still overlap & $\begin{array}{l}\text { "Sometimes, we experience overlapping of tasks. In some parts, nurses completing duties that } \\
\text { should have be conducted by physicians, even though nurses do not want to do that actually. } \\
\text { However, because our goal is patient safety, most nurses still keep on that, here there is a } \\
\text { problem. } \\
\text { The main obstacle that we still do a lot of action that really is not our job as nurses." (P9) } \\
\text { "I should deliver an infusion therapy, injection, and suturing the wound. Those aren't my duties, } \\
\text { the tasks are merely delegated verbally, unwritten." (Pl1) } \\
\text { "In the pre-conference session conducted regularly, you also have to manage the work tasks, } \\
\text { divide it and delegate it to other nursing staff. } \\
\text { I just ask myself, is it my duty? dividing the task should be involved in head of ward } \\
\text { responsibility, } \\
\text { not me..., whose job is it??" (P5) }\end{array}$ \\
\hline & $\begin{array}{l}\text { Male nurses do more urgent } \\
\text { services than female nurses }\end{array}$ & $\begin{array}{l}\text { “... I think the men job was blur. In emergency field, as you can see, always male allocated here. } \\
\text { There is limited number of female nurses in the emergency ward" (P4) } \\
\text { "If another room needs resuscitation help, usually we are nurses of men who often come, female } \\
\text { nurses a little dodge." (P12) }\end{array}$ \\
\hline
\end{tabular}


Table 2. Themes, sub-themes, and participants' statements about assertiveness barriers in collaboration implementation for the care of patient with ACS in emergency departments

\begin{tabular}{|c|c|c|}
\hline Theme & Sub-theme & Participant' statement/keyword \\
\hline \multirow[t]{2}{*}{$\begin{array}{l}\text { Difference of } \\
\text { confidence between } \\
\text { senior and junior } \\
\text { nurses in caring for } \\
\text { ACS patients }\end{array}$} & $\begin{array}{l}\text { Senior nurses note that the } \\
\text { mistakes made were } \\
\text { minimal }\end{array}$ & $\begin{array}{l}\text { "If there is a case of ACS, as far as I know, it is handled by senior nurses. Based on our } \\
\text { experience, the senior has only a minimal error rate once... (P4) } \\
\text { "Expertise maybe depends on the experience of handling ACS. Our nurses, ventilator and } \\
\text { defibrillators are already here in } 24 \text { hours. It is important, we must know where we work. We } \\
\text { learn to understand what is happening and must know the procedure to avoid mistakes." (P8) }\end{array}$ \\
\hline & $\begin{array}{l}\text { Junior nurses are less } \\
\text { confident and more } \\
\text { confused }\end{array}$ & $\begin{array}{l}\text { Generally, the junior activities include administering an intravenous infusion, providing } \\
\text { something, just like that. Here, we need a fast response, } 4 \text { minutes or } 5 \text { minutes, junior nurses } \\
\text { often get doubt and face obstacles to follow the speed." (P4) } \\
\text { "I am still afraid and confused to do collaboration, because I just joined the ED." (P9) } \\
\text { "If there are too many patients, usually for treating ACS patients, I consult with a more senior } \\
\text { nurse. I help the patient as much as I can do such as apply an infusion therapy or ECG. } \\
\text { Sometime I got less confident because I have little experience about the ECG procedure." (PII) } \\
\text { "Even junior nurses held bachelor degree, they cannot be guaranteed in understanding ACS, } \\
\text { this may happened because they were newbies as emergency nurses, so we as senior nurses } \\
\text { should hold more roles and guide them." (P15) }\end{array}$ \\
\hline
\end{tabular}

Table 3. Themes, sub-themes, and participants' statements about autonomy barriers in collaboration implementation for the care of patient with ACS in emergency departments

\begin{tabular}{|c|c|c|}
\hline Theme & Sub-theme & Participant' statement/keyword \\
\hline \multirow[t]{2}{*}{$\begin{array}{l}\text { Limitation for } \\
\text { performing professional } \\
\text { nursing practice }\end{array}$} & $\begin{array}{l}\text { Limited authority to address triage } \\
\text { decision making }\end{array}$ & $\begin{array}{l}\text { "There is an emergency physician. So sorry, it seems that our presence are ignored. We } \\
\text { have to waiting for the physician order..." (P2) } \\
\text { "So, who is the responsible person for determining ACS patients in the first priority, or } \\
\text { the second priority? } \\
\text { It is a right of the physician, nurses have limited authority. If the doctor is wrong, } \\
\text { however, the nurse has to straighten it up." (P7) }\end{array}$ \\
\hline & $\begin{array}{l}\text { Limited chance of nursing } \\
\text { documentation }\end{array}$ & $\begin{array}{l}\text { "The medical record will be carried by the cardiologist lead to difficulties to completed } \\
\text { the nursing documentation as the forms have to filled are incorporated in the medical } \\
\text { record." (P12) } \\
\text { "Then another constraint is the patient' medical record is often be carried by the } \\
\text { physician." (P15) }\end{array}$ \\
\hline
\end{tabular}

Table 4. Themes, sub-themes, and participants' statements about cooperation barriers in collaboration implementation for the care of patient with ACS in emergency departments

\begin{tabular}{|c|c|c|}
\hline Theme & Sub-themes & Participant' statement/keyword \\
\hline \multirow[t]{2}{*}{$\begin{array}{l}\text { Unclear } \\
\text { nursing job } \\
\text { description }\end{array}$} & $\begin{array}{l}\text { The job duties still } \\
\text { overlap }\end{array}$ & $\begin{array}{l}\text { "In the pre-conference session conducted regularly, you also have to manage the work tasks, divide it and } \\
\text { delegate it to other nursing staff. I just ask myself, is it my duty? dividing the task should be involved in head } \\
\text { of ward responsibility, not me..., whose job is it?" (P5) "Sometimes, we experience overlapping of tasks. In } \\
\text { some parts, nurses completing duties that should have be conducted by physicians, even though nurses do } \\
\text { not want to do that actually. However, because our goal is patient safety, most nurses still keep on that, here } \\
\text { there is a problem. The main obstacle that we still do a lot of action that really is not our job as nurses." } \\
(P 9) \\
\text { "I should deliver an infusion therapy, injection, and suturing the wound. Those aren't my duties, the tasks } \\
\text { are merely delegated verbally, unwritten." (P11) }\end{array}$ \\
\hline & $\begin{array}{l}\text { Male nurses do more } \\
\text { urgent services than } \\
\text { female nurses }\end{array}$ & $\begin{array}{l}\text { "... I think the men job was blur. In emergency field, as you can see, always male allocated here. There is } \\
\text { limited number of female nurses in the emergency ward" (P4) } \\
\text { "If another room needs resuscitation help, usually we are nurses of men who often come, female nurses a } \\
\text { little dodge." (P12) }\end{array}$ \\
\hline
\end{tabular}

\section{DISCUSSION}

\subsection{Difference Of Confidence Between Senior And Junior Nurses In Caring For Acs Patients}

Rapid response and responsiveness are important for helping patients in the ED. Therefore, it is important that nurses should be able to manage patients with ACS as well as to recognize the signs and symptoms [16]. This response can be done by senior and junior nurses. For senior nurses, this is not an obstacle because the nurses already have a longer clinical experience than the junior nurses. Agnew and Flin show that in difficult and emergency conditions, the role of senior nurses is needed to maintain patients' safety and stability [19]. Unlike the newly enrolled registered nurses, although considered competent, they do not always feel confident to do so. 
Professional confidence is very important for nurses in order to provide quality care for ACS patients at the emergency departments. Qualitative research conducted by Ortiz shows that the participants did not feel confident because they were unable to communicate well with the senior nurses, and made mistakes\due to lack of experience. The support of managers in providing interpersonal collaboration opportunities and knowledge development opportunities can help increase nurses' confidence in the collaboration [20].

\subsection{Limitation For Performing Professional Nursing Practice}

According to Souza et al., collaboration is an essential way of organizational practice to improve the quality of health, safety, patients' satisfaction and employment [1]. The intended collaboration consists of interdisciplinary collaboration i.e. physicians with nurses and among nurses. A study Khademian indicated that cooperation can be achieved if it provides effectiveness, clarity of roles, effective patient management, and the ability to resolve the problem to the team members [8]. In the service process, the nurses have a limitation in performing medical measures, but they are allowed to provide inputs or suggestions. A nurse as a working partner is allowed to provide input based on evidence and their knowledge. The importance of cooperation between nurses and physicians should be widely recognized. Improved communication and good information delivery have been reported to reduce medical errors [12, 13].

One of the limitations of nurses in collaboration is related to triage decision making. In some countries in the Americas and Europe, decision making for triage can be done by nurses and a team of health professionals including physicians and nurses $[5,6]$. The right of a physician is to determine the patient's priority in the triage, but there are some physicians who do not want to receive nurses' feedback when they make wrong triage decisions. This can lead to misunderstandings between physicians and nurses.

Another limitation that the nurses perceived is the writing of nursing care documentation. Nursing documentation is a part of the patient's medical record which is an important communication tool for health care providers [10]. This research reveals that the documents that should be filled by nurses are sometimes still filled by specialists, which makes it difficult for nurses to do further nursing care. Almidani, Khadawardi, Alshaaref and Saadeh in their research show the need for a change from the quality management team to improving compliance with the clinical documentation despite many challenges. Major improvements can be achieved when collaboration and efforts involving stakeholders are set as common goals.

\subsection{Unclear Nursing Job Description}

Unclear nursing job is a frequent phenomenon that requires immediate solutions. Lack of clarity about the role performed requires some nurses to perform the same activities every day. Nurses feel uncomfortable with the unclear job divisions. Research conducted by Standing and Anthony [2008] indicates that nurses want clear task regarding components; delegation structure, delegation process, and communication [4].

Effective communication and relationship patterns are very important to be created in the crowded condition of the EDs. Research conducted by Moore Weaver found that many nurses are out of work because the relationship between nurses in the room is not well [9]. This is in line with the literature review by Milton which indicates that the relationships and communication between nurses in the room are still not as expected [11]. This delegation is only verbal, not written or legalized. The same opinion was expressed by Mueller and Vogelsmeier [2013] that the delegation process from middle manager to nurses or from physicians to nurses should be based on the basic principle of public protection [14]. When used effectively, delegates can lead to safer and longer-time patient care for a registered nurse to deal with more complex patient care.

The next factor is the unclear job description of nurses. This study found that male nurses work more than female nurses. Research conducted showed that differences in motivation and skills between male and female have long been considered as an important factor in the gender gap, but this factor is difficult to measure [21]. Significant changes occur due to increased female's participation in the workforce, assuming that females are more capable of solving problems, analyzing, and providing competitive encouragement, motivation, and sociability in relation to performance [22].

\section{CONCLUSION}

The results of the study showed that there were obstacles in three aspects of the collaboration process namely assertiveness, autonomy and cooperation in treating ACS patients in the emergency departments. Nurses, especially junior, assertively acknowledge their lack of confidence. Also, nurses experience autonomy limitations in making triage decisions and difficulty in documenting nursing actions. Nurses also experience obstacles in cooperating with both physician and fellow nurses to treat patients with ACS in the EDs. Based on the results, it is important to carry out inter-professional education initiations for nursing and medical students, apply peer-mentoring to increase the self-confidence of junior nurse, develop and train the clinical pathway of collaboration between physicians and nurses for the care of ACS patients in EDs. Further research is needed to develop a model of nurse-physician collaboration based on work culture and regulations regarding their role in EDs.

\section{AUTHORS CONTRIBUTION}

All authors contributed to the concept of the study, design, collection data, analysis data, and manuscript preparation.

\section{FUNDING}

This research was funded by Medical Faculty, Universitas Brawijaya.

\section{ETHICS APPROVAL AND CONSENT TO PARTICIPATE}

Ethics approval for this research has been obtained from the Medical Research Ethics Committee of Medical Faculty, 
University of Brawijaya, Malang, Indonesia, with letter number: 216/EC/KEPK/06/2017.

\section{HUMAN AND ANIMAL RIGHTS}

No animals/humans were used for studies that are the basis of this research.

\section{CONSENT FOR PUBLICATION}

Not applicable.

\section{CONFLICT OF INTEREST}

The authors declare that they have no conflict of interests in this research and article writing.

\section{ACKNOWLEDGEMENT}

The authors would like to thank all parties who have assisted in the completion of this article, especially to the supervisor.

\section{REFERENCES}

[1] Souza GC, Peduzzi M, Silva JA, Carvalho BG. Teamwork in nursing: restricted to nursing professionals or an interprofessional collaboration? Rev Esc Enferm USP 2016; 50(4): 642-9. [http://dx.doi.org/10.1590/S0080-623420160000500015] [PMID: 27680051]

[2] Khoshchehreh M, Groves EM, Tehrani D, Amin A, Patel PM, Malik $\mathrm{S}$. Changes in mortality on weekend versus weekday admissions for Acute Coronary Syndrome in the United States over the past decade. Int J Cardiol 2016; 210: 164-72.

[http://dx.doi.org/10.1016/j.ijcard.2016.02.087] [PMID: 26950171]

[3] Mol KA, Rahel BM, Meeder JG, van Casteren BCAM, Doevendans PA, Cramer MJM. Delays in the treatment of patients with acute coronary syndrome: Focus on pre-hospital delays and non-ST-elevated myocardial infarction. Int J Cardiol 2016; 221: 1061-6.

[http://dx.doi.org/10.1016/j.ijcard.2016.07.082] [PMID: 27448533]

[4] Siegler EL, Whitney FW, He Y, Guo Y. Nurse-physician Collaboration. New York: Springer Publishing Company 2000.

[5] Liao C, Qin Y, He Y, Guo Y. The Nurse-Nurse Collaboration Behavior Scale: Development and psychometric testing. Int J Nurs Sci 2015; 2(4): 334-9.

[6] Smith A, Cone KJ. Triage decision-making skills: a necessity for all nurses. J Nurses Staff Dev 2010; 26(1): E14-9.

[http://dx.doi.org/10.1097/NND.0b013e3181bec1e6] [PMID: 20098 163]

[7] Hudson PV, Marshall AP. Extending the nursing role in Emergency Departments: Challenges for Australia. Australas Emerg Nurs J 2008; 11(1): 39-48.

[http://dx.doi.org/10.1016/j.aenj.2007.11.003]
[8] Pfaff KA, Baxter PE, Jack SM, Ploeg J. Exploring new graduate nurse confidence in interprofessional collaboration: a mixed methods study. Int J Nurs Stud 2014; 51(8): 1142-52.

[http://dx.doi.org/10.1016/j.ijnurstu.2014.01.001] [PMID: 24486164]

[9] Ortiz J. New graduate nurses' experiences about lack of professiona confidence. Nurse Educ Pract 2016; 19: 19-24. [http://dx.doi.org/10.1016/j.nepr.2016.04.001] [PMID: 27428687]

[10] Yaman Aktas Y, Kucuk Alemdar D. Triage Decision-Making Levels of Healthcare Professionals Working in Emergency Departments. Eurasian J Emerg Med 2017; 16(3): 92-6.

[http://dx.doi.org/10.5152/eajem.2017.96168]

[11] Moore LW, Leahy C, Sublett C, Lanig H. Understanding nurse-tonurse relationships and their impact on work environments. Medsurg Nurs 2013; 22(3): 172-9. [PMID: 23865278]

[12] Khademian Z, Sharif F, Tabei SZ, Bolandparvaz S, Abbaszadeh A, Abbasi HR. Teamwork improvement in emergency trauma departments. Iran J Nurs Midwifery Res 2013; 18(4): 333-9. [PMID: 24403932]

[13] Milton CL. Leadership and ethics in nurse-nurse relationships. Nurs Sci Q 2009; 22(2): 116-9.

[http://dx.doi.org/10.1177/0894318409332569] [PMID: 19342708]

[14] Almidani E, Khadawardi E, Alshareef T, Saadeh S. International Journal of Pediatrics and Departmentsal collaborative approach for improving in-patient clinical documentation (five years experiences). Int J Pediatr Adolesc Med 2018; pp. 1-6.

[15] Jansen $H$. The logic of qualitative survey research and its position in the field of social research methods [63 paragraphs]. Forum Qualitative Sozialforschung / Forum: Qualitative. Soc Res (New York) 2010; 11(2): 11.http://nbnresolving.de/urn:nbn:de:0114-fqs1002110

[16] Wihastuti TA, Rachmawati SD, Kumboyono, Harista DR, Lestari YC, Rahmawati I, et al. Qualifications of Emergency Nurse in Caring the Acute Coronary Syndrome Patient: The Perspective of Rural Hospitals in Indonesia. Indian J Public Heal Res Dev 2017; 8(4)

[17] Speziale HS, Streubert HJ, Carpenter DR. Qualitative Research in Nursing: Advancing the humnistic imperative. 5th ed. Philadelphia: Lippincott William \& Wilkins 2011; p. 470

[18] Reiners GM. Nursing \& Care Understanding the Differences between Husserl's (Descriptive) and Heidegger's (Interpretive). Phenomenological Research 2012; 1(5): 1-3.

[19] Joob B, Wiwanitkit V. Acute chest pain: what about the time before visiting to the physician? J Acute Dis 2013; 2(4): 330-1. [http://dx.doi.org/10.1016/S2221-6189(13)60154-7]

[20] Agnew C, Flin R. Senior charge nurses' leadership behaviours in relation to hospital ward safety: a mixed method study. Int J Nurs Stud 2014; 51(5): 768-80.

[http://dx.doi.org/10.1016/j.ijnurstu.2013.10.001] [PMID: 24200223]

[21] Mueller C, Vogelsmeier A. Effective Delegation: Understanding Responsibility, Authority, and Accountability. J Nurs Regul 2013; 4(3): 20-7.

[http://dx.doi.org/10.1016/S2155-8256(15)30126-5]

[22] Muench U, Dietrich H. The male-female earnings gap for nurses in Germany: A pooled cross-sectional study of the years 2006 and 2012. Int J Nurs Stud 2017; (July): 1-7.

[PMID: 28716298]

\section{(C) 2019 Wihastuti et al.}

This is an open access article distributed under the terms of the Creative Commons Attribution 4.0 International Public License (CC-BY 4.0), a copy of which is available at: (https://creativecommons.org/licenses/by/4.0/legalcode). This license permits unrestricted use, distribution, and reproduction in any medium, provided the original author and source are credited. 